\title{
JOÃO DO RIO E ROBERTO ARLT [CRÔNICA, FOTOGRAFIA E CINEMA] JOÃO DO RIO AND ROBERTO ARLT [CHRONICLE, PHOTOGRAPHY AND CINEMA]
}

\author{
Eleonora Frenkel ${ }^{1}$
}

Resumo: Em 1930, Roberto Arlt escreve uma crônica elogiando o fotógrafo Aniceto Martínez por sua bravura e dedicação na cobertura de eventos variados da vida urbana. O profissionalismo desse repórter se elevaria à categoria de arte moderna e Aniceto se tornaria "artista de circunstâncias". A fotografia aparece como recurso do jornalismo moderno, assim como a crônica se desenvolve nesse ímpeto de registro circunstancial. No Brasil, João do Rio escrevera, anos antes, um livro de crônicas intitulado Cinematógrafo (1908), afirmando que esse gênero literário teria "evoluído" da fotografia para a arte do cinema. O que este texto propõe pensar são os movimentos de atração e repulsão entre as artes da crônica, da fotografia e do cinema, bem como os procedimentos e modos de leitura que as aproximam e que as afastam.

Palavras-chave: Roberto Arlt, João do Rio, Crônica, Fotografia, Cinema.

\begin{abstract}
In 1930, Roberto Arlt writes a chronicle about Aniceto Martínez, praising his bravery and dedication on the photographic coverage of the different urban daily life events. The professionalism of this reporter would elevate his work to the category of modern art and Aniceto would be an "artist of circumstances". Photography appears as a modern journalism resource, as well as chronicles develop towards the registration of circumstances. At Brazil, João do Rio had written, years before, a chronicle book entitled Cinematographer (1908), where he says that this literary gender would have
\end{abstract}

1 Eleonora Frenkel (Universidade Federal de Santa Catarina) 
"progressed" from photography to the art of cinema. This text proposes to think the attraction and repulsion movements among the arts of chronicle, photography and cinema, as well as the procedures and ways of appraisal which may bring together or separate the three of them.

Keywords: Roberto Arlt, João do Rio, Chronicle, Photography, Cinema.

\section{Crônica fotográfica e fotografia narrativa}

"Un fotógrafo extraoridinario"2 é uma crônica que Roberto Arlt escreve em homenagem ao fotógrafo ("reportero gráfico") Aniceto Martinez, onde elogia diversas cenas de sua atuação profissional e de sua capacidade de registrar os acontecimentos mais tensos e relevantes de sua época. A edição de Cronicón de si mismo (Edicom, 1969) que apresenta essa crônica toma de empréstimo seu título e a coloca como subtítulo, numa possível articulação entre as atuações do cronista e do fotógrafo e num gesto de indistinção entre ambas as artes. A própria crônica de Arlt se escreve como em tomadas fotográficas, breves notas que recortam cenas diversas e as reúnem como num pequeno álbum que percorre momentos de uma viagem.

Seria Arlt um Aniceto das palavras? Seriam suas crônicas um registro quase fotográfico de seu tempo? Arlt identifica em Aniceto o olhar de um narrador repórter, aquele que articula em sua fotografia uma leitura e uma narrativa da história. A crônica, por sua vez, surgiria justamente desse cruzamento entre o jornalismo e a literatura, uma narrativa que extrapola a reportagem jornalística e se abre para a ficção, mas que mantém por vezes o cordão atado aos eventos do cotidiano que lhe dão os primeiros sopros de vida.

João do Rio, um dos precursores no Brasil do que Foot Hardman chama de "ensaios de grafismo urbano" (1992: 539), escrituras diversas da cidade moderna, intitula suas "crônicas cariocas" de Cinematógrafo (1908). ${ }^{3}$ Aqui, o contato entre as artes não se dá entre a fotografia, uma cena estática, e a crônica, mas entre esta e o cinema. João do Rio pensa a crônica em comparação ao cinematógrafo: "a grande história visual do mundo" (RIO, 1909:. ix). E isso se coloca como uma "evolução", como um avanço moderno do gênero literário que, em sua origem, seria "reflexão e comentário", passando pelo desenho, pela caricatura e pela fotografia para, finalmente, se configurar como um "cinematógrafo de letras, o romance da vida do

2 Publicada no jornal El Mundo, Buenos Aires, 17/02/1930.

3 E Flora Sussekind toma o título da crônica de João do Rio para seu livro: "Cinematógrafo de letras”. Literatura, técnica e modernização no Brasil. SP: Cia das Letras, 1987. 
operador no labirinto dos fatos, da vida alheia e da fantasia" (RIO, 1909: $\mathrm{x})$. O interessante é que essa "passagem" da crônica de "fotografia retocada mas sem vida" a cinematógrafo vem acompanhada de um paulatino processo de "aliviamento" da mesma de seu conteúdo explicativo, dando maior relevo ao encantamento da invenção.

O cinema aparece como fenômeno "extra-moderno", "resultado de uma resultante de um resultado científico moderno" (RIO, 1909: viii) e sabemos que a imprensa moderna ganha força e, por sua vez, fortalece, tanto à crônica quanto à fotografia, de modo que podemos pensar como lê-las em sua articulação, em seus movimentos de atração e repulsão, como manifestações artísticas singulares, porém integradas, que leem e propõem leituras de um tempo passado, ao passo que são lidas e reabertas num presente sempre novo.

\section{Suportes para guardar o que não deixa de escapar...}

Derivada da palavra grega para designar o tempo, Chronus, a crônica seria uma forma de "escrita do tempo" ou um tipo de "lugar da memória", um espaço onde a linguagem tentaria guardar os acontecimentos e deixá-los registrados como comentário, crítica ou ficção a ser reaberta num futuro próximo ou distante. É um espaço em que o presente se torna passado ao ser escrito e se atualiza como um agora a cada nova leitura. Mais do que um registro do passado, a crônica viria a ser, então, um espaço em que os tempos se entrecruzam. Essa seria, aliás, a definição mesma da memória para Henri Bergson: a sobrevivência de imagens passadas que se misturam à percepção do presente (2000: 69). Uma reflexão que também pode ser retomada na teoria da história de Walter Benjamin, que é uma teoria da memória, entendida como aquela que (re)inscreve o passado no presente, sobrepondo os tempos e rompendo a suposta linearidade da História. ${ }^{4}$

A questão que passa por aí é que, para "guardar a memória", o cronista, enquanto narrador de um tempo vivido, deve lidar com o intermédio da linguagem, que se faz tanto uma ferramenta quanto um obstáculo. Como disse Guillermo Fadanelli, ${ }^{5}$ entre o real e a ficção está a linguagem:

4 Ver: W. Benjamin. Sobre o conceito da História. In: Magia e técnica, arte e política, 1994.

5 Em evento celebrado na Fundación Tomás Eloy Martínez, Buenos Aires, durante a realização do IV Festival Internacional de Literatura (Filba 2012), onde se discutiu a crônica, em especial as de Carlos Monsiváis. O título da conversa foi "Las aguafuertes después de Monsiváis" e parte dela está disponível para consulta em: http://blog.eternacadencia.com.ar/archives/2012/25058. 
Fazendo uma grande abstração, tudo o que se escreve é ficção. Quando você escreve um ensaio e acredita que está lidando com a realidade, tem a linguagem como intermediária. E essa linguagem nos precede: já existia antes de que nos sentássemos a escrever, e não a dominamos de todo. Pensar que dominamos a fronteira entre ficção e não ficção é algo ambicioso. ${ }^{6}$

Ao pensar a fotografia e o texto, Roland Barthes dirá que a primeira tem a "referência" como "ordem fundadora", que ela seria algo como o "real no estado passado" (1984: 115 e 124), e que a linguagem, ao contrário, teria o infortúnio de não poder autenticar-se a si mesma, o que a tornaria ficcional por natureza. Ou seja, por mais que a crônica traga uma exposição do in situ, uma exibição do "ter estado ali", ela contém uma carga ineludível de ficção e o referente se apresenta nela tão somente como ausência, como linguagem que manifesta o que já não está mais ali; assim como a fotografia, que, a despeito do que diz Barthes, implica um recorte e uma leitura que falseiam a referência e impedem sua apreensão exata.

Foot Hardman parte dessa "verdade referencial" da fotografia, da qual fala Barthes, e diz que ela lhe dá sua "força significante", mas que só se tem acesso ao referente da imagem pelos discursos possíveis de a envolver, de modo que ele se torna também um constructo da linguagem e, enquanto tal, uma referencialidade escorregadia. As fotografias aparecem como ruínas da história, cujo referente garante um "valor indiciário" que irá inspirar narrativas que procurarão reescrever esse tempo capturado e, nesse sentido, diz Hardman: "ao buscar as pegadas do fotógrafo-cronista, caminha-se rápido da prosa historiográfica para a de ficção" (1992: 531 e 547).

A crônica e a fotografia, enquanto lugares da memória ou restos da história são pensadas, assim, menos por sua capacidade de registro circunstancial do que pela força que contém de revelar como atualizamos e (re)inventamos o passado no presente. De modo concomitante, como dirá Margarida Neves, há uma recolocação da relação entre ficção e história: as crônicas (e as fotografias, podemos acrescentar) se apresentam como

6 Tradução minha do fragmento: "Haciendo una gran abstracción-comenzó Fadanelli -todo lo que se escribe es ficción. Cuando escribes un ensayo y crees que estás lidiando con la realidad, tienes al lenguaje como intermediario. $Y$ ese lenguaje nos precede: ya existía antes de que nos sentáramos a escribir, y no lo dominamos del todo. Pensar que dominamos la frontera entre ficción y no ficción es algo ambicioso" (Em: http://blog.eternacadencia.com.ar/archives/2012/25 058\#more-25058).

7 Como o diz Damián Tabarovsky na mesma conversa citada acima: "La crónica tiene una puesta en escena de lo in situ, del haber estado alli" (Em: http://blog.eternacadencia.com.ar/archives/2 012/25058\#more-25058). 
"imagens de um tempo social" ou como "narrativas do cotidiano", mas não se tomam como documentos ou dados e sim como construções (1992: 76). Nesse sentido, proponho pensar um pouco mais nos procedimentos de recorte e montagem como parte dessa construção.

Walter Benjamin destaca, em seu ensaio sobre a reprodutibilidade técnica na modernidade, que o cinema como obra de arte surge através da montagem, é ela que dá aos fragmentos e "acontecimentos não-artísticos" o caráter de arte, na medida em que coloca em ação os diversos recursos técnicos de que dispõem para criar um objeto estético, capaz de provocar uma percepção não apenas ótica, mas principalmente tátil, baseada na "mudança de lugares e ângulos, que golpeiam intermitentemente o espectador" (BENJAMIN, 1985:178 e 192).

As reflexões e experimentos sobre a montagem no cinema começam a ganhar força com Eisenstein e Dziga Vertov, ${ }^{8}$ mas não é apenas na sétima arte que se explora o procedimento. Ele aparece também nas fotomontagens de Aleksandr Ródtchenko, nas colagens de Pablo Picasso ou nas composições dadaístas de Tristan Tzara, ${ }^{9}$ como um modo de provocar a percepção, de ampliar a hesitação diante do objeto artístico, de deslocar a compreensão de um suposto sentido unívoco e de ampliar as ressonâncias dos sentidos. ${ }^{10}$

8 Serguei Eisenstein afirma em 1925 que "existe apenas um método para fazer qualquer filme: a montagem de atrações" (Eisenstein, Da revolução à arte, p. 33); ele desenvolve sua teoria, buscando o modo de orientar a percepção dos espectadores mediante a montagem singular da sequência de imagens. O filme de Dziga Vertov, Man with a movie camera (1929) foi um dos primeiros a expor o processo criativo mediante a explicitação dos cortes; a ilusão de realidade buscada pelo cinema hollywoodiano de David Griffith, com seus cortes imperceptíveis, é quebrada pelo cinema russo em que se celebra o papel do câmera e do editor no processo criativo; no filme de Vertov, o olho que edita se expõe.

9 A receita de Tristan Tzara para escrever um poema dadaísta é: pegar jornal e tesoura, selecionar um artigo e recortar nele algumas palavras, colocá-la em um saco, agitar suavemente, tirar uma a uma as palavras do saco e copiá-las "conscienciosamente" na ordem em que são tiradas. Essa montagem singular e ocasional daria um poema "infinitamente original" (In:TELES, 2009: 171).

$10 \mathrm{Na}$ esteira desses experimentos, Victor Chlovski escreve "A arte como procedimento" (1917), onde discute a concepção de poesia como criação de imagens e defende a tese de que esta deve provocar o estranhamento por meio da singularização da composição, o que implica uma montagem original dos signos, retirados de seu uso e combinações convencionais; com isso, a arte buscaria dar a sensação do objeto como visão e não como reconhecimento, sendo que a primeira seria a percepção duradoura motivada pelo efeito de desfamiliarização (CHLOVSKI, 1971: 50). Walter Benjamin distingue algo semelhante ao pensar o cinema: a distração e a contemplação, sendo a primeira um modo de percepção provocado por um efeito de choque que se potencializa pela montagem singular das imagens. A recepção por distração integra, segundo Benjamin, uma "reestruturação do sistema perceptivo" que passaria a ser predominantemente tátil e não mais apenas ótico; um intuito que os dadaístas já procurariam e que o cinema conseguiria realizar (BENJAMIN, 1994: 194).

Organon, Porto Alegre, v. 28, n. 55, p. 73-85, jul./dez. 2013. 
A apresentação de João do Rio a seu Cinematógrafo explicitará também o recorte, o ângulo e o modo de disposição como instâncias do processo de criação da crônica. Se um conjunto de crônicas se configura igualmente como uma "grande história visual do mundo", ele também se faz ciente de que "ninguém pode exatamente repetir com a mesma emoção e o mesmo estado d'alma um ato da existência", de modo que ambos, a crônica e o cinema, se expõem em sua "modesta e gloriosa" capacidade de "arrolar" a vida atual, qual seja, de fazer o inventário ou reunir a coleção daquilo que se considera valioso e relevante:

Um rolo de cem metros na caixa de um cinematografista vale cem vezes mais que um volume de história - mesmo porque não tem comentários filosóficos. E, isso porque no fundo o cinematógrafo é uma série de novelas e de impressões pessoais do operador à procura do 'bom momento', é a nota do seu temperamento a escolher o assunto já feito, e a procurar as posições para tomar a fita. (RIO, 1909: ix)

O "bom momento" é uma escolha, o posicionamento é um recorte e o modo de composição é um arranjo singular que reconfigura os elementos selecionados no grande arquivo da vida. ${ }^{11}$ A crônica parece se distanciar da história e da filosofia para se aproximar do espetáculo artístico.

\section{Ilusão da captura}

Em sua origem medieval, a crônica se entenderia como narrativa histórica, inclusive as crônicas e diários de viajantes ao continente americano assumiriam o caráter de documentos e registros oficiais das viagens de conquista dos novos territórios. Margarida Neves fala da acepção colonial

11 Vale a pena lembra a passagem de Charles Baudelaire que Walter Benjamin recorta, onde o poeta se compara ao trapeiro, aquele que chafurda no tumulto dos dejetos, faz uma triagem, uma seleção e arma com eles sua coleção: "O trapeiro é a figura mais provocadora da miséria humana. Lumpemproletário num duplo sentido: vestindo trapos e ocupando-se de trapos. 'Eis um homem encarregado de recolher o lixo de cada dia da capital. Tudo o que a cidade grande rejeitou, tudo o que ela perdeu, tudo o que desdenhou, tudo o que ela destruiu, ele cataloga e coleciona. Ele consulta os arquivos da orgia, o cafarnaum dos detritos. Faz uma triagem, uma escolha inteligente; recolhe, como um avaro um tesouro, as imundícies que, ruminadas pela divindade da Indústria, tornar-se-ão objetos de utilidade ou de prazer." [...] Como se constata nesta descrição em prosa de 1851, Baudelaire se reconhece no trapeiro" (BENJAMIN, 2007: 395. A passagem de Baudelaire citada pode ser encontrada, em francês, em: "Du vin et du hachisch", Les Paradis Artificiels, Paris, Librairie Générale Française, 2000, p. 64). 
da crônica, que se pretendia registro ou narração dos eventos e suas circunstâncias em sua ordenação cronológica, tal como estes teriam ocorrido "de fato". Na virada do século XIX para o XX, a crônica não perderia seu caráter de narrativa e registro, mas incorporaria uma "qualidade moderna: a do lugar reconhecido à subjetividade do narrador" (NEVES, 1992: 82). Além disso, a crônica vinculada ao jornal impresso combina o comentário das questões políticas, sociais, artísticas e literárias do dia-a-dia, com criações de maior "densidade literária", o que lhe permite ampliar os horizontes em relação a esse suporte fugaz e descartável que é o jornal e adquirir maior durabilidade. ${ }^{12}$

É interessante pensar, por exemplo, na coluna de crônicas do jornal $E l$ Mundo, escrita por Roberto Arlt a partir de 1935 e intitulada Tiempo presente. Elas são, em sua maioria, comentários de acontecimentos nacionais e internacionais que inspiram e incomodam o escritor desde sua viagem à Espanha e África e de seu contato com a guerra civil. Carregada de teor histórico, essa memória do presente registrada há tantas décadas torna-se um passado em devir que o leitor atualiza e recria a partir de seus referentes; a experiência subjetiva do escritor resta na escritura apenas como ausência e os dados factuais que ali se anotam se reinventam nas novas narrativas que se farão dela.

A análise que Foot Hardman faz de uma série de fotografias de Dana Merrill que registraram a construção da ferrovia Madeira-Mamoré na selva amazônica ${ }^{13}$ aponta para esse modo de leitura que reabre as imagens/ os textos a partir daquilo que evocam para o observador/leitor e, nessa abertura, percebe a fragilidade de reconstrução do referente, bem como reconhece que a narrativa que delas se fará constrói um percurso apenas possível que procura agarrar esse espaço-tempo ausente e fugidio.

Foot Hardman pensa a fotografia como fonte para a "prosa historiográfica”, já apontando o limite tênue entre ela e a ficção, e diz que as imagens, embora mudas, evocam "certa capacidade de linguagem", mas esta precisaria ser desprendida por um texto que as decifrasse. Das fotos partiria

12 "Sobre a "espessura de texto literário" que a crônica adquire, ver: ARRIGUCCI Jr. (1997: 53). Sobre o crescimento articulado da crônica e do jornal impresso: "Retificando o que ficou dito atrás, ela não nasceu propriamente com o jornal, mas só quando este se tornou cotidiano, de tiragem relativamente grande e teor acessível, isto é, há uns 150 anos mais ou menos [...] Antes de ser crônica propriamente dita foi 'folhetim', ou seja, um artigo de rodapé sobre as questões do dia - políticas, sociais, artísticas, literárias. Assim eram os da secção 'Ao correr da pena', título significativo a cuja sombra José de Alencar escrevia semanalmente para o Correio Mercantil, de 1854 a 1855" (CANDIDO, 1992: 15).

13 Essas fotos foram retomadas pela narrativa de Manuel Rodrigues Ferreira: A ferrovia do diabo (1960).

Organon, Porto Alegre, v. 28, n. 55, p. 73-85, jul./dez. 2013. 
um trabalho de escavação e reconstrução que, ao passo que promove uma reaproximação ao espaço-tempo em que foram capturadas, o elo que estabelece se revela falível e passível de distanciar a narrativa do referente. Há uma história que se cria e que exibe "a ilusão da captura de um tempo", que manifesta a impossibilidade de cristalizar o tempo passado e voltar a observá-lo "tal como era". O que dele se escreve é mais uma atualização fugaz e impermanente. Nesse sentido, a fotografia, enquanto suporte de memória ou registro de um tempo seria também uma "crônica do efêmero", uma narrativa do tempo que não deixa de passar. Foot dirá:

Frágil e fragmentária por definição, converte-se, pois, nos deslocamentos da memória que desencadeia, em instrumento mágico do registro lacônico que revela quase nada, esconde quase tudo, mas sugere, por aquele momento passageiro aparentemente estacionado, gestos expressivos, paisagens e fisionomias revolvidas, numa palavra, experiências dignas de serem reescritas e transmitidas. (HARDMAN, 1992: 532)

A questão seria também ressaltar que o "digno" de ser transmitido será sempre um recorte subjetivo e fragmentário, de modo que, completa Foot: as fotografias seriam ruínas contemporâneas da civilização técnica sobre as quais o historiador constrói seus discursos, ciente da "descontinuidade que lhe dá fundamento" (HARDMAN, 1992: 533). A narrativa viria marcada por uma tentativa de "resgate da memória" que não pode elidir seu caráter de constructo sobre o constructo (o recorte, a montagem, a singularidade da imagem) que se arma dessa maneira, mas que poderia ser feita por outro percurso.

De modo análogo à montagem que, no cinema, transforma os "acontecimentos não-artísticos" em obra de arte, há um procedimento de recorte e colagem que se dá tanto no olhar do fotógrafo quanto daquele que lê a fotografia, bem como na escritura e leitura da crônica. O cinema como narrativa, como continuidade e movimento, já é resultante dessa armação que será percebida pelo espectador.

\section{Corte e Montagem}

Se a crônica teria como princípio básico o registro do circunstancial, segundo Jorge de Sá (2002: 6), há que se pensar quais circunstâncias procurará destacar e, portanto, qual será o recorte escolhido. Se a fotografia, como diria Cartier Bresson, é a arte da captura do "momento decisivo" ou 
da cena exata no tempo certo (Apud ANDRADE, 1992: 493), há que se considerar também que uma boa foto não é feita somente do evento que registra, mas fundamentalmente da luz que a envolve. Assim como um tema banal pode ser como um sol em um conto, ${ }^{14}$ um evento cotidiano pode se tornar excepcional em uma crônica e uma cena sem grandes acontecimentos pode dar uma bela foto. De modo que a circunstância em si não faria da narrativa ou da imagem objetos de arte especialmente expressivos. Luz, recorte e montagem se mostram fundamentais para tal.

João do Rio, ao pensar a "crônica como um gênero gêmeo à cinematografia" (NEVES, 1992: 84), nos lembra que há movimento na narrativa, que ela é linguagem em desdobramento, que está composta de cenas que se abrem e deslocam, às quais o leitor é aproximado e afastado; há perspectivas e contornos, idas e vindas, close-ups e flashbacks. Na crônica, mais do que os fotogramas isolados, tratar-se-ia do modo de montá-los, de sua forma de disposição e arranjo no texto.

Mas o interessante é que, a despeito desse "isolamento" da imagem fotográfica, há também narrativa e movimento na fotografia. Como diz Ana M. Andrade, "fixando imagens no espaço/tempo, a fotografia cria uma narrativa" (1992: 493). Mais do que isso, Andrade destaca que a imprensa jornalística passou a fazer da fotografia justamente um uso narrativo. $\mathrm{O}$ primeiro magazine semanal que deu preferência às fotos, segundo ela, foi The illustrated London News, fundado em 1842. E os semanários da virada do século XIX para o XX teriam começado a reconhecer a importância da câmera como meio de ilustração, a ponto de, a partir de 1930, desenvolver-se uma linguagem fotográfica: o fotojornalismo. Andrade diz:

Rapidez na imagem captada, na imagem reproduzida e na composição do texto final, compondo, a partir dos anos 30 deste século, uma linguagem fotográfica: o fotojornalismo, linguagem imbuída de caráter fundamentalmente didático e de um controle rígido da correlação texto/imagem por parte da equipe editorial. Seguindo essa nova tendência, as fotos não eram simplesmente espalhadas no texto, mas com diferentes tamanhos e formas; começaram a ser deliberadamente arranjadas, rompendo esquemas tradicionais de tamanho. Muitas vezes ultrapassavam uma página inteira, invadindo a página lateral. Esse tipo de programação visual criou a fama de revistas como a Life, Paris Match, Look e O Cruzeiro no Rio de Janeiro. (ANDRADE, 1992: 495)

14 Em suas considerações sobre o conto, Julio Cortázar diz que "um bom tema é como um sol, um astro em torno do qual gira um sistema planetário de que muitas vezes não se tinha consciência até que o contista, astrônomo de palavras, nos revela sua existência" (2006: 154). 
O modo de arranjo das fotografias na página se torna algo fundamental, um recurso explorado para criar movimento entre elas, para promover um percurso narrativo com elas e ampliar as significações em sua leitura.

O que me leva, por sua vez, a algumas considerações sobre o modo de ler. Haveria ao menos duas grandes vertentes: a leitura interpretativa e descritiva, que procuraria reconstituir uma intencionalidade de escritura (ou de captura na fotografia) e uma referencialidade contextual; e a leitura de suspensão de sentido, que buscaria a percepção dos procedimentos de composição e o destaque das aberturas e questionamentos deixados pelo texto ou pela imagem.

Roland Barthes, em Câmara clara, a despeito de destacar a referência como ordem fundadora da fotografia, propõe um modo de leitura que não prioriza o resgate do referente. Este seria identificado na exploração de um dos elementos da fotografia, o studium, um vasto campo que o espectador percebe na imagem a partir de seus saberes, de sua cultura. Ele remeteria ao campo de interesse cultural aberto pela fotografia. Mas o que de fato interessa a Barthes é o que quebra o studium, o segundo elemento da fotografia: o punctum, o "detalhe descentrado" (1984: 78), aquele aspecto na imagem que não se explica, que fica fora do contexto, que desestabiliza ou inquieta a fixidez da imagem. Ela deixa de ser algo fechado e passível de reconstituição integral para ser uma inquietante abertura.

Barthes diz: "punctum é também picada, pequeno buraco, pequena mancha, pequeno corte - e também lance de dados. O punctum de uma foto é esse acaso que, nela, me punge (mas também me mortifica, me fere)" (1984: 46). O que fere seria justamente aquilo que revela a incompletude de todo o saber e toda a cultura, sua incapacidade de abarcar e explicar de modo cabal. Seria aquilo para o qual não se encontra nome e que resta como pergunta: "O que posso nomear não pode, na realidade, me ferir", de modo que "a impotência para nomear é um bom sintoma de distúrbio" (1984: 80). Identificamos o punctum quando fechamos os olhos e percebemos o que resta na memória da imagem como perturbação. Ele seria um "campo cego" ou um ponto de fuga, algo que leva para fora do enquadramento, "uma espécie de extracampo sutil, como se a imagem lançasse o desejo para além daquilo que ela dá a ver: não somente para 'o resto' da nudez, não somente para o fantasma de um ser, alma e corpo intricados" (1984: 86 e 89).

O punctum seria de fácil percepção no haikai, esse poema conciso que traz um verso que funciona como um detalhe detonador, como o estopim que deflagra uma abertura para além do poema, para uma entrelinha que pode ser escrita de tantas formas e jamais fixada como única. Seria possível pensar algo assim para a leitura da crônica, um procedimento não prag- 
mático que se ocupa menos do valor documental ou comunicacional do texto, ${ }^{15}$ para pensar o que punge, o que incomoda e suspende a compreensão, ao passo que abre as significações? Roberto Arlt, em uma crônica em que dialoga com um leitor que lhe conta sobre uma discussão que tivera com um interlocutor que acusava os textos de Arlt de serem pastéis e não águas-fortes, ${ }^{16}$ responde:

Quando o senhor me pergunta se o que escrevo são ou não águas-fortes, não sei dizer que sim ou que não. Sei que às vezes, a certas pessoas, minhas notas ferem como ácido nítrico. E é com esse ácido que se grava no metal o desenho dessa classificação: águas-fortes. (ARLT, 1998: 377) ${ }^{17}$

O que se destaca na água-forte seria a violência de suas imagens, a punção que provocam e o que as excede, ou melhor, o que resta para fora delas como suspensão de pergunta e inquietação. Provocações de leitura de uma modernidade disparatada que se apresenta sobre o signo da Razão e que deixa tanto sem explicação.

Segundo João do Rio, a arte do cinema, enquanto grande panorama da vida, nasce de uma despretensão geral tanto do "operador", "que não se imagina um ser excepcional", quanto daqueles que assistem às "fitas", que "não se julgam na obrigação de julgar ver coisas importantes para a sua opinião definitiva"; o que se fixa no cinematógrafo (e, subentenda-se, nas crônicas que a ele se comparam) é a ilusão: "a única verdade resistente no mundo subsolar" (RIO, 1909: vii). O que se destaca para a crônica em tempos "extra-modernos" não é a explicação e sim o engano e o erro; dela não partiria um registro definitivo das verdades de uma época, mas dela se faria uma porta de abertura para a imaginação: "Se a vida é um cinematógrafo colossal, cada homem tem no crânio um cinematógrafo de que o

15 Terry Eagleton fala da leitura pragmática, que seria ler um texto ficcional (que se caracteriza por criação singular de técnicas narrativas) destacando seu valor documental ou comunicacional. E sobre a operação inversa: ler um texto documental ou comunicacional de modo a destacar seu valor metafórico ou sua ambiguidade. Eagleton dirá: "Qualquer fragmento de escrita pode ser lido 'não pragmaticamente', se é isso o que significa ler um texto como literatura, assim como qualquer escrito pode ser lido 'poeticamente."' (2006: 13-14).

16 O leitor conta na carta supostamente encaminhada a Arlt e reproduzida na crônica: "Yo quise sostener su nombre y fue inútil. En otro rincón un provinciano exclamó': - 'Eso no son aguafuertes, sino que son pasteles' 'Al final de la polémica, se quedó en que no eran aguafuertes, contra mi opinión, claro está." (ARLT, 1998: 376).

17 Tradução minha do fragmento: "De modo que cuando usted me pregunta si lo que yo escribo son o no aguafuertes, no sé si decirle que sí o que no. Sé que a veces, a cierta gente, mis notas le pican como ácido nítrico. Y con este ácido es con el que se graba en metal el diseño de esa clasificación: aguafuertes." (ARLT, 1998: 377).

Organon, Porto Alegre, v. 28, n. 55, p. 73-85, jul./dez. 2013. 
operador é a imaginação" (RIO, 1909: viii). O grande operador da crônica viria a ser a imaginação daquele que a lê, a sua capacidade de criar imagens a partir dos objetos ausentes evocados pela linguagem. O grande cinematógrafo de letras aparece como:

[Um] romance em que o operador é personagem secundário arrastado na torrente dos acontecimentos. Esta é a sua feição, o desdobramento das fitas, que explicam tudo sem reflexões, e como o século está cansado de pensar, e como a frase verdadeiramente exata da humanidade na fartura dos casos é o clássico: - já vi! o operador escreve despreocupado, pouco lhe importando que vejam a fita, que compreendam ou não, ou que tornem a vê-la. (RIO, 1909: xi)

O século XX começara há menos de uma década e já estava cansado de pensar e a crônica apareceria aqui como mais uma alternativa para se aliviar do peso da racionalidade. Nesse sentido, ela aparece despojada da necessidade de correção, podendo vagar como registro passageiro de um tempo ao qual não se terá tempo de voltar: "Não houve tempo de reler para notar defeitos - mesmo porque não há tempo para nada" (RIO, 1909: xi). Já não havia tempo para nada e a modernidade rapidamente se configura como o tempo da falta de tempo. O cinematógrafo, enquanto resultado extra-moderno só poderia ser, então, uma arte do efêmero, sujeita à constante novidade do moderno: "A grande ideia dos que mudam o aparelho da reprodução da vida seria que os espectadores esquecessem o que já disseram na fita passada para sentir a novidade da próxima" (RIO, 1909: xi). Se a crônica se configura tal qual o cinema, ela seria um fragmento fugaz que reúne os restos de memória daquilo que facilmente se poderia esquecer e que, no entanto, compõe os arquivos da história a serem reabertos à luz das imaginações presentes, que não o restituem tal qual foi e sim que o criam conforme àquilo se quer dele fazer a cada nova atualização de leitura.

\section{BIBLIOGRAFIA}

ANDRADE, Ana M. Crônica fotográfica do Rio de Janeiro na primeira metade do século XX. In: CANDIDO, Antônio et alii. A crônica: o gênero, sua fixação e suas transformações no Brasil. Campinas, SP: Editora da Unicamp; Rio de Janeiro: Fundação Casa de Rui Barbosa, 1992.

ARLT, Roberto. El paisaje en las nubes. Crónicas en El Mundo 1937-1942. Buenos Aires: Fondo de Cultura Económica, 2009. 
. Obras. Aguafuertes. Tomo II. Buenos Aires: Losada, 1998. . Notas sobre el cinematógrafo. Buenos Aires: Simurg, 1997.

. Cronicon de si mismo. Buenos Aires: Edicom, 1969.

ARRIGUCI Jr., Davi. Fragmentos sobre a crônica. In: ___. Enigma e comentário. Ensaios sobre literatura e experiência. São Paulo: Companhia das Letras, 1987.

BARTHES, Roland. A câmara clara. Nota sobre a fotografia. Tradução de Júlio C. Guimarães. Rio de Janeiro: Nova Fronteira, 1984.

BENJAMIN, Walter. Passagens. Edição Alemã de Rolf Tiedemann; organização da edição brasileira Willi Bolle; tradução do alemão de Irene Aron; tradução do francês de Cleonice P. B. Mourão. Belo Horizonte: Editora UFMG; São Paulo: Imprensa Oficial do Estado de São Paulo, 2007. . Magia e técnica, arte e política. Tradução de Sergio P. Rouanet. São Paulo: Brasiliense, 1994.

BERGSON, Henri. Matéria e memória. São Paulo: Martins Fontes, 2000. CANDIDO, Antônio et alii. A crônica: o gênero, sua fixação e suas transformações no Brasil. Campinas, SP: Editora da Unicamp; Rio de Janeiro: Fundação Casa de Rui Barbosa, 1992.

Chklovski, Victor. A arte como procedimento. In: EIKHENBAUM, B. et alii. Teoria da Literatura (Formalistas russos). Tradução de Ana M. Ribeiro et alii., POA: Globo, 1971.

CORTÁZAR, Julio. Valise de cronópio. Tradução Davi Arriguci Jr. e João Alexandre Barbosa; organização de Haroldo de Campos e Davi Arriguci Jr. São Paulo: Perspectiva, 2006.

EAGLETON, Terry. Teoria da literatura. Uma introdução. Tradução de Waltensir Dutra. São Paulo: Martins Fontes, 2006. HARDMAN, Foot. Os negativos da história. In: CANDIDO, Antônio et alii. A crônica: o gênero, sua fixação e suas transformações no Brasil. Campinas, SP: Editora da Unicamp; Rio de Janeiro: Fundação Casa de Rui Barbosa, 1992.

NEVES, Margarida. Uma escrita do tempo. In: CANDIDO, Antônio et alii. A crônica: o gênero, sua fixação e suas transformações no Brasil. Campinas, SP: Editora da Unicamp; Rio de Janeiro: Fundação Casa de Rui Barbosa, 1992. SÁ, Jorge de. A crônica. São Paulo: Ática, 2002.

TELES, Gilberto Mendonça. Vanguarda européia \& Modernismo brasileiro. Apresentação e crítica dos principais manifestos vanguardistas. RJ: Vozes, 2009.

Recebido em 25/08/2013. Aceito em: 13/10/2013. 